\title{
A CIÊNCIA ABERTA E A ÁREA DE EDUCAÇÃO EM CIÊNCIAS: PERSPECTIVAS E DIÁLOGOS
}

\author{
Paula Cristina Cardoso Mendonça ${ }^{1}$ \\ https://orcid.org/0000-0003-1762-4840
}

\author{
Luiz Gustavo Franco ${ }^{2}$ \\ https://orcid.org/0000-0002-1009-7788
}

O conhecimento científico é uma construção humana e de natureza social, considerando que as práticas sociais e as ações padronizadas por determinadas comunidades científicas, que são reconhecidas e internalizadas entre os seus membros, guiam o trabalho científico, isto é, os processos de produção, comunicação, avaliação e legitimação do que conta como uma afirmativa de conhecimento válida (Kelly, 2008).

É a natureza social do trabalho científico que nos capacita lidar de forma mais crítica com a questão objetividade versus subjetividade inerente à ciência. Como argumenta Longino (1990), sendo produzido por uma comunidade, o conhecimento científico transcende a contribuição de um único indivíduo (ou uma subcomunidade daquele todo), uma vez que as hipóteses e conclusôes são produzidas de modo coletivo através de uma convergência de pontos de vista, como também de discordâncias. Ou seja, a partir de interaçóes discursivas críticas, estabelecidas pelas comunidades científicas (Longino, 2002), que se torna possível garantir uma maior objetividade das ciências "não por canonizar uma subjetividade frente às outras, mas por assegurar que o que é ratificado como conhecimento sobrevive à crítica de múltiplos pontos de vista” (Longino, 2002, p. 129). Portanto, o que é aceito como conhecimento científico sobreviveu às críticas de diversas naturezas impostas pelo escrutínio público.

Uma revista científica apresenta um papel muito importante nas interações discursivas críticas para o estabelecimento do que conta como conhecimento. Longino (2002) nos apresenta critérios e normas que devem balizar as interações discursivas críticas, de modo a torná-las mais efetivas na produção de conhecimento. A seguir os apresentamos e estabelecemos relaçóes com o papel de um periódico científico:

- Fóruns públicos de discussão: refere-se ao reconhecimento da necessidade de fóruns públicos para crítica de evidências, métodos, raciocínios e conclusóes relacionados à pesquisa científica. Os fóruns podem acontecer na forma de discussão em encontros científicos e nos periódicos especializados. A crítica nos fóruns pode favorecer a avaliação das hipóteses, da metodologia e da relação dela com as questôes de pesquisa, conduzindo a melhor apreciação dos resultados da investigação. As interaçôes discursivas críticas acontecem em vários momentos do desenvolvimento do trabalho científico nas comunidades, mas a avaliação por pares (peer review) é sem dúvida uma das marcas contemporâneas da legitimação do conhecimento. A avaliação por pares é um método acadêmico que visa avaliar e garantir a qualidade, a completude e a originalidade de um trabalho acadêmico. Tem como objetivo melhorar o trabalho acadêmico conforme os critérios de qualidade tomados pelo periódico em diálogo com o campo disciplinar (Ross-Hellauer \& Görögh, 2019).

- Receptividade à crítica: significa que a comunidade científica deve estar aberta às críticas e modificações de princípios que balizam determinada pesquisa, aceitando e revendo suas declaraçôes, argumentando e considerando o princípio da igualdade moderada de autoridade intelectual.

\footnotetext{
${ }^{1}$ Universidade Federal de Ouro Preto, Departamento de Química \& Programa de Pós-graduação em Educação. Ouro Preto, MG, Brasil

${ }^{2}$ Universidade Federal de Minas Gerais, Departamento de Métodos e Técnicas de Ensino \& Programa de Pós-graduação em Educação, Conhecimento e Inclusão Social. Belo Horizonte, MG, Brasil
} 
- Igualdade moderada de autoridade intelectual: nas comunidades deve ocorrer uma distribuição da autoridade intelectual de forma igualitária de maneira que o que conta é o posicionamento quanto à pesquisa e não apenas o status de determinado pesquisador ou grupo de pesquisa.

- Padrôes públicos de análise: envolve critérios que balizam a aceitação ou rejeição de determinadas pesquisas e que são compartilhados e públicos numa determinada comunidade. Isto se torna importante uma vez que inviabiliza a desqualificação enviesada das pesquisas a partir do uso de padrôes arbitrários. Estes critérios podem modificar-se através do tempo em função de novos padrões, objetivos e valores acordados na comunidade. Da mesma forma que ocorre com o julgamento do conhecimento, tais padróes de análise também estão susceptíveis a análise crítica.

Nos fundamentando em tais critérios e normas da produção social do conhecimento, neste editorial temos como objetivo apresentar novas práticas que serão implementadas pelo periódico Ensaio Pesquisa em Educação em Ciências neste quadriênio. Elas estão em consonância com o paradigma Ciência Aberta recomendado pela Scielo e outras editoras e plataformas que operam com práticas que vão em direção contrária à comercialização da ciência e a privacidade do conhecimento. De forma geral, Ciência Aberta consiste em um movimento da comunidade acadêmica de tornar a pesquisa científica (em termos de seus produtos e processos) acessíveis e utilizáveis por todos (SciELO, 2018). Os pilares do movimento Ciência Aberta são: transparência, reutilização de dados de pesquisas, reprodutibilidade de resultados e metodologias, cooperação e responsabilidade. As principais práticas a serem implementadas em periódicos, conforme este movimento, são (SciELO, 2018):

- acesso livre: virtual, sem quaisquer restrições (incluindo as financeiras) a todos artigos científicos publicados em periódicos acadêmicos;

- preprints: consiste no depósito do manuscrito completo, identificado e inédito pelos autores em servidores de preprints (como por exemplo, arXiv, bioRXiv, scielo preprints, preprints.org, F1000, OSFpreprints) antes de serem enviados para análise em um periódico científico para sua validação pela revista. O objetivo é acelerar a divulgação da pesquisa e garantir autoria das novas ideias, processos e descobertas. Um vez carregado em um servidor preprint público, o manuscrito é identificado com um DOI e o acesso é público. Os autores, ao submeterem o manuscrito para avaliação em um periódico, informam a revista o identificador DOI do trabalho depositado no servidor.

- repositório de dados da pesquisa e códigos de programação: consiste no depósito em repositórios dos códigos de programa e dados da pesquisa, que são acompanhados de metadados para definição de autoria dos pesquisadores. O depósito dos dados deve ser feito considerando os princípios éticos que delineiam o desenvolvimento da pesquisa. Considerando que dados podem ser analisados de distintas formas segundo as lentes teóricas do pesquisador, o objetivo de compartilhar dados de pesquisa visa favorecer a reutilização em outras investigaçôes, também auxilia na avaliação do manuscrito, na preservação dos dados e reprodutibilidade. Levando-se em conta que o financiamento das pesquisas é prioritariamente feito pela iniciativa pública, considera-se que o reuso de dados pode contribuir para o bom uso do investimento público na pesquisa.

- open peer review: Normalmente, na área de Educação em Ciências, o processo de avaliação por pares se dá de modo duplo cego, de maneira que nem os autores e nem os revisores são revelados uns aos outros. A prática de realização de revisóes abertas (conhecido como open peer review, denominado aqui de OPR) tem ganhado destaque na agenda do paradigma Ciência Aberta, tendo como objetivos principais promover maior participação nas produçóes científicas, dando mais transparência aos processos de arbitragem, evitando parcialidades, e incenti- 
vando a participação e parceira dos avaliadores nas revisões de manuscritos, a partir do crédito que é dado aos mesmos, uma vez que os pareceres são publicados assim como os artigos aceitos para publicação (Ross-Hellauer \& Görögh, 2019). As práticas sociais das comunidades científicas são aprendidas a partir da participação, ou seja, do envolvimento dos indivíduos com elas. Algumas vezes isso implica em interações prolongadas dos indivíduos com os membros já familiarizados com as formas pelas quais se produz, comunica, avalia e legitima o conhecimento dentro da comunidade (Kelly \& Licona, 2018). Nesse sentido, além dos fatores já destacados de vantagens do uso de OPR, a publicação de pareceres torna-se uma ação educativa para aqueles iniciantes na comunidade. Inclusive, porque alguns relatórios destacam que os pareceres costumam ganhar em qualidade e consistência (Ross-Hellauer \& Görögh, 2019). Por outro lado, algumas pesquisas mostram que autores ou revisores preferem não relevar as identidades (não assinando pareceres, por exemplo) por questôes de conflitos interpessoais e políticos (Bornmann, Herich, Joos, \& Daniel, 2012). Deste modo, torna-se importante que cada comunidade reflita sobre os benefícios de OPR objetivando critérios para sua implementação a partir das diversidades possíveis de abertura de identidades (abertura total ou parcial das identidades, abertura para a comunidade de um modo geral, interação aberta, por exemplo) e dos diferentes modos pelos quais pareceres podem ser publicados (seguido do artigo, fóruns, colocado no artigo com comentários, por exemplo) (Ross-Hellauer, Deppe, \& Schmidt, 2017).

O acesso livre e a publicação de forma contínua já são práticas adotadas pela revista Ensaio Pesquisa em Educação em Ciências alinhadas à perspectiva Ciência Aberta. A partir deste ano começamos a adotar o formulário Scielo Ciência Aberta (disponível em três idiomas) a ser preenchido por todos os autores na submissão do manuscrito, informando se o mesmo já está disponível em algum servidor preprint e o identificador. Também será questionado se pretende ou não disponibilizar os materiais suplementares da pesquisa em algum tipo de repositório.

Levando em conta que a prática de OPR é bastante promissora, porém limitada na nossa área, iremos realizar um estudo piloto nos anos de 2021 e 2022 de implementação desta prática para um eixo temático da área de Educação em Ciências. A partir das experiências, buscaremos avaliar caminhos para um processo orgânico de trabalho com OPR. Aqui apresentamos de modo sucinto o caminho que nos guiou a esta escolha.

No ano de 2020, os membros da equipe editorial da Revista Ensaio Pesquisa em Educação em Ciências $^{1}$ buscaram avaliar criticamente os procedimentos e refletir sobre as demandas de autores e pareceristas da revista. Além disso, nos dedicamos a pensar sobre os rumos do periódico diante da crise persistente que assola a comunidade brasileira de pesquisadores e de professores e que impacta a produção acadêmica do nosso país.

Em uma dessas análises, realizamos um levantamento sobre as temáticas dos artigos publicados no periódico no período de 2017 a 2019, considerando os eixos temáticos de eventos relevantes da área, como os propostos no último Encontro Nacional de Pesquisa em Ensino de Ciências (ENPEC). Constatamos um baixo número de artigos em determinadas áreas, a saber: Educação em Saúde e Educação em Ciências; Questões teóricas e metodológicas da pesquisa e Diferenças, multiculturalismo e interculturalidade.

Nesse sentido, seguindo o plano editorial da revista alinhado à perspectiva Ciência Aberta (o qual busca equidade, diversidade e inclusão), buscamos por políticas que visam favorecer um maior número de submissões relacionadas às temáticas expostas anteriormente.

Esta proposta visa contribuir para a realização de um dos nossos objetivos mais caros: o de tornar a revista Ensaio um periódico mais diverso e, portanto, mais representativo para a área de Educação em Ciências.

Para que a comunidade se junte a nós, dando continuidade a proposta deste editorial, apresentaremos 
no mês de março de 2021 uma carta convite a autores interessados em publicar trabalhos na linha temática 'Diferenças, multiculturalismo e interculturalidade', esclarecendo as diretrizes do processo avaliativo do tipo OPR. A escolha de OPR se justifica pela tentativa de qualificar o debate sobre a temática, reconhecer o esforço dos autores e revisores e, em termos práticos, acompanhar o piloto de delineamento desta prática editorial mais de perto, refletindo sobre as suas diretrizes de implementação e resultados. Desse modo, na carta convite, delineamos também os caminhos metodológicos que serão adotados pela revista no processo de OPR, convidando pareceristas a atuarem conjuntamente conosco nesta empreitada.

Cordialmente, nos despedimos desejando um diálogo cada vez mais aberto em nossa comunidade.

Editores chefes da Revista Ensaio Pesquisa em Educação em Ciências

Paula Cristina Cardoso Mendonça \& Luiz Gustavo Franco

\section{REFERÊNCIAS}

Bornmann, L., Herich, H., Joos, H., \& Daniel, H.-D. (2012). In public peer review of submitted manuscripts, how do reviewer comments differ from comments written by interested members of scientific community? A content analisys if comments written for atmospheric chemistry and physics. Scientometrics, 93(3), 915-929.

Kelly, G. (2008). Inquiry, actitivity and epistemic practice. In R. Duschl \& R. Grandy (Eds.), Teaching scientific inquiry: recommendations for research and implementation (pp. 288-291). Rottherdan: Holand: Tapei Sense Publishers

Kelly, G., \& Licona, P. (2018). Epistemic practices and science education. In M. Matthews (Ed.), History, Philosophy and Science Teaching: New perspectives Springer International Publishing.

Longino, H. E. (1990). Science as a social knowledge: Values and objectivity in scientific inquiry. New York: Princenton.

Longino, H. E. (2002). The fate of knowledge. Princenton: Princenton University Press.

Ross-Hellauer, T., Deppe, A., \& Schmidt, B. (2017). Survey on open peer review: attitudes and experiente amongst editors, authors and reviewers. PLoS One, 12(12), e0189311.

Ross-Hellauer, T., \& Görögh, E. (2019). Guidelines for open peer review implementation. Research integrity and Peer Review, 4(4), 1-12.

SciELO, Scientific Eletronic Library Online.. (2018). Linhas prioritárias de ação 2019-2023. Disponível em [online]: https://www.scielo20.org/redescielo/wp-content/uploads/sites/2/2018/09/L\%C3\%ADneas-prioritaris-deacci\%C3\%B3n-2019-2023_pt.pdf

\section{NOTAS}

1 Registramos nosso agradecimento ao editores Geide Coelho Rosa, Glauco dos Santos Ferreira da Silva e Vanessa Cappelle que assumiram esta tarefa.

\section{Paula Cristina Cardoso Mendonça}

Licenciada em Química, Mestre e Doutora em Educação

Professora Associada da Universidade Federal de Ouro Preto, Departamento de Química \& Programa de Pós-graduação em Educação. 


\section{Luiz Gustavo Franco}

Licenciado em Ciências Biológicas, Mestre e Doutor em Educação

Professor Adjunto da Universidade Federal de Minas Gerais, Departamento de Métodos e Técnicas de Ensino \& Programa de Pós-graduação em Educação, Conhecimento e Inclusão Social.

Contato:

Centro de Ensino de Ciências e Matemática - CECIMIG Faculdade de Educação da Universidade Federal de Minas -FaE

Av. Antônio Carlos, 6627,Belo Horizonte - MG | Brasil CEP 31.270-901 Tel.: 55(31) 3409-5338

revistaepec@gmail.com 